\title{
COLOSTOMIA TIPO HARTMANN EM RATOS: ALTERAÇÕES MORFOLÓGICAS E DOSAGEM DE HIDROXIPROLINA
}

\author{
HARTMANN'S COLOSTOMY IN RATS: MORPHOLOGYC ALTERATIONS \\ AND HYDROXYPROLIN CONTENTS
}

\author{
João Carlos Simões, TCBC-PR ${ }^{1}$ \\ Paola Brolin Santis ${ }^{2}$ \\ Ricardo Ribeiro Gama ${ }^{2}$ \\ André Luiz Bini ${ }^{2}$ \\ Márcio Barboza Cardoso ${ }^{2}$ \\ João Carlos Repka ${ }^{3}$
}

\begin{abstract}
RESUMO: A colostomia tem sido um procedimento cirúrgico freqüentemente empregado nas doenças colônicas, lesões traumáticas e neoplásicas. Este trabalho experimental, em ratos, visou estudar as progressivas mudanças morfológicas no cólon proximal e distal, após uma laparotomia e colostomia terminal, tipo Hartmann, que foram estudadas histologicamente e através da dosagem tecidual de hidroxiprolina. Utilizaram-se 40 ratos, machos, raça Wistar, com peso médio de 200 gramas, alocados em dois grupos (grupo I ou experimento e grupo II ou controle), subdivididos em quatro subgrupos: A,B,C e D com 10 animais em cada subgrupo. Os animais do grupo I (subgrupos A e B) foram submetidos à colostomia tipo Hartmann, no cólon distal, a 7,5cm do canal anal. Nos ratos do grupo II foi praticada apenas uma laparotomia mediana. Os animais dos subgrupo A e C foram sacrificados no 30 dia de P.O., enquanto que os animais dos subgrupos B e D o sacrifício foi no $60^{\circ}$ dia de P.O. A análise histológica dos segmentos colônicos permitiu observar infiltrado inflamatório agudo e crônico na lâmina própria, achatamento pronunciado das criptas, diminuição do número de criptas e da celularidade epitelial, redução das células caliciformes e da mucossecreção, adelgaçamento da muscular da mucosa, mais intensos no coto colônico distal dos animais submetidos à colostomia terminal tipo Hartmann (subgrupos A e B). Os segmentos proximais apresentavam estas alterações, porém mais discretas. A dosagem de hidroxiprolina nos tecidos colônicos não revelou alterações estatisticamente significativas quanto ao conteúdo de colágeno ou do peso desidratado. Estes achados permitem demonstrar alterações morfológicas inflamatórias e hipotróficas mais pronunciadas no cólon distal de ratos submetidos à colostomia tipo Hartmann.
\end{abstract}

Unitermos: Colostomia tipo Hartmann; Hidroxiprolina; Ratos

\section{INTRODUÇÃO}

O desvio do trânsito fecal, através da colostomia, é um procedimento cirúrgico, temporário ou definitivo, largamente utilizado para descomprimir o lado esquerdo do cólon em casos de obstrução ou para prevenir as complicações das anastomoses colorretais.

Quando Henri Hartmann descreveu a cirurgia que hoje recebe o seu nome, em 1921, ela foi indicada para o tratamento paliativo de um carcinoma de cólon ${ }^{1}$. Mais recentemente, Boyden (citado por Belmante ${ }^{1}$ ) popularizou a técnica cirúrgica para correção das complicações da doença diverticular, para a qual ela tem se tornado, hoje em dia, um procedimento básico.

Recentemente, alguns autores têm dado maior atenção às alterações morfológicas hipotróficas e inflamatórias verificadas no cólon, após desvio do trânsito intestinal determinado pela colostomia ${ }^{2-4}$. Contudo, pouco se conhece

1. Professor Titular da Disciplina de Técnica Cirúrgica e Cirurgia Experimental da FEMPAR. Chefe do Serviço de Oncologia do HUEC.

2. Médico Residente do Serviço de Oncologia do HUEC

3. Professor Titular da Disciplina de Microbiologia e Imunologia da FEMPAR

Recebido em 22/4/99

Aceito para publicação em 25/5/2000

Trabalho Realizado no Laboratório da Disciplina de Técnica Cirúrgica e Cirurgia Experimental da FEMPAR e Serviço de Oncologia do Hospital Univeristário Evangélico de Curitiba - HUEC 
sobre as mudanças citocinéticas, morfológicas e do conteúdo de colágeno e seus derivados nos segmentos intestinais, após procedimentos cirúrgicos que promovam sua desfuncionalização e as consequiências que isto possa ter em relação à cicatrização das anastomoses, ao aumento da morbidade e mortalidade após as decolostomias ${ }^{5-10}$.

O objetivo deste estudo experimental, em ratos, foi, através de observação histológica e pela mensuração do conteúdo tecidual de hidroxiprolina, investigar, qualificar e quantificar as alterações morfométricas do cólon distal e proximal, após colostomia tipo Hartmann.

\section{MATERIAL E MÉTODOS}

Foram utilizados 40 ratos brancos, machos, da raça Wistar, provenientes do Instituto Tecnológico do Paraná (TECPAR), com peso médio de 200 gramas. Os animais tiveram livre acesso à água e à ração (padronizada) durante o experimento.

Eles foram alocados em dois grupos e subdivididos em quatro subgrupos, de acordo com o dia de sacrifício:

- Grupo I ou experimento $(n=20)$ : subgrupos A $(n=10)$ e $\mathrm{B}(\mathrm{n}=10)$ nos quais os animais foram submetidos à laparotomia mediana e à colostomia terminal tipo Hartmann e sacrificados no $30^{\circ}$ e $60^{\circ}$ dias de P.O., respectivamente .

- Grupo II ou controle $(n=20)$ : subgrupo C $(n=10)$ e D $(\mathrm{n}=10)$ cujos ratos foram submetidos à laparotomia mediana apenas e aos sacrificados no $30^{\circ}$ e $60^{\circ}$ dia, respectivamente.

\section{Anestesia}

Todos os animais receberam anestesia inalatória com éter sulfúrico após jejum de 12 horas.

\section{Técnica Cirúrgica}

Após a anestesia, os animais eram imobilizados à mesa cirúrgica de cortiça em decúbito dorsal, sendo feita a raspagem do abdome e antissepsia com povidine tintura. Os ratos foram submetidos à laparotomia mediana de, aproximadamente, $5 \mathrm{~cm}$ de extensão.

\section{Grupo I ou Experimento - subgrupos A e B}

Foi introduzida por via retal, em cada animal de ambos os grupos, uma sonda nasogástrica no $\mathbf{6}$, marcada em milímetros. O cólon distal foi seccionado ao nível da marca de $14 \mathrm{~mm}$. O coto distal foi fechado através de sutura contínua tipo chuleio simples, de pontos seromusculares com justaposição de bordas, plano único, utilizandose fio de poliglactina $910 \mathrm{com}$ revestimento de poliglactina 370, no 6.0. O cólon proximal foi exteriorizado através da parede abdominal, na região da fossa ilíaca esquerda. A incisão da colostomia foi realizada de forma circular. Fezse a sutura seromuscular do coto proximal do cólon distal na aponeurose da parede abdominal, com pontos separados, dispostos em pontos cardeais, com fio de poliglactina 910 com revestimento de poliglactina $370, \mathrm{n}^{\mathrm{o}}$ 6.0. Posteriormente, foi realizada a maturação precoce do cólon na pele da parede abdominal utilizando-se o mesmo fio.
O fechamento da parede abdominal foi realizado em dois planos, utilizando-se fio de poliglactina 910 número 5-0.

\section{Grupo II ou Controle - subgrupos C e D}

Nos animais deste grupo, após a realização da laparotomia mediana, a parede abdominal foi fechada de maneira semelhante ao grupo experimento. Os animais foram sacrificados no $30^{\circ}$ e no $60^{\circ}$ dias de P.O. por inalação com éter sulfúrico. $\mathrm{O}$ abdome foi aberto através de incisão contornando a cicatriz anterior, resultando em uma "janela" para melhor visualização das alterações intraperitoneais. Identificado o coto distal, este foi extirpado, conservando margem de tecido colônico normal. Procedeu-se à ressecção ao redor da boca da colostomia, juntamente com secção de tecido normal colônico proximal. Cada segmento extirpado foi dividido em duas peças, uma era fixada em formalina a $10 \%$, desidratada, embebida em parafina, para posterior confecção de lâminas, enquanto que a outra foi congelada para as dosagens de hidroxiprolina.

\section{Histologia}

Os blocos de parafina contendo as peças foram submetidos a cortes longitudinais com espessura de 6 micrômetros. As lâminas foram confeccionadas e coradas por hematoxilina-eosina e avaliadas histologicamente por microscopia ótica. Todas as lâminas, referentes a cada animal estudado, foram analisadas por um mesmo patologista do Serviço de Patologia do Hospital Universitário Evangélico de Curitiba. Este empregou o método qualitativo subjetivo, comparando a espessura da mucosa do cólon nos cortes transversais e as alterações histopatológicas do cólon normal (grupo controle) com o segmento proximal e distal dos animais colostomizados.

\section{Dosagem de Hidroxiprolina}

Para a dosagem da hidroxiprolina tecidual foi adotada a técnica fotocolorimétrica utilizando-se a metodologia proposta por Ibbott, em 1974 ${ }^{11}$.

\section{ESTATÍSTICA}

Para análise estatística foi utilizado o teste $t$ de Student, com nível para rejeição da hipótese de nulidade de $\mathrm{p}<0,05 \%$ e submetido à comparação estatística através do teste de Fisher.

\section{Resultados}

A colostomia estava funcionante em todos os animais do grupo I ou experimento. A pele ao redor da colostomia apresentava-se íntegra, com ausência de celulite, fístulas, herniações ou macerações. A incisão cirúrgica da laparotomia achava-se com área de fibrose no local e plenamente cicatrizada. Abscessos, deiscências, herniações não foram encontrados nesses animais. 
Após o sacrifício, a cavidade abdominal foi inspecionada e observado se havia aderências do omento e alças vizinhas ao redor do segmento proximal da colostomia. Também foram encontradas bridas entre as alças vizinhas, omento e órgãos vizinhos (epidídimo, intestino delgado) no coto distal. Em todos os animais dos subgrupos A e B estas aderências foram facilmente divulsionadas propiciando visualização das estruturas estudadas.

Nos animais do subgrupo B o coto distal do cólon apresentava-se hipotrófico, sendo difícil sua localização. Em dois animais deste mesmo subgrupo, devido à impossibilidade de definir a presença do coto distal, fez-se necessária a introdução de sonda nasogástrica ํㅡㅇ 6 , via retal e, em seguida, ressecção deste segmento. Três animais do subgrupo A e um do subgrupo B encontravam-se com abscesso no local da sutura de fechamento do coto distal do cólon, que apresentava-se bloqueado pela gordura omental. Não foram visualizadas deiscências de sutura ou fístulas no coto distal. Na abertura da peça, a mucosa estava intacta, não apresentando deiscência de sutura.

O coto proximal encontrava-se íntegro, sem evidências de processo inflamatório. Em cinco animais ocorreu dilatação discreta do cólon proximal à colostomia. Procedendo a abertura do coto proximal visualizou-se mucosa íntegra, sem evidências de abscessos, deiscências ou fístulas.

\section{Análise Histológica}

\section{- Coto Proximal}

Observou-se presença de inclusão mural de mucosa em áreas de sutura, com reparo fibrovascular cicatricial esclerosado. Reação de corpo estranho, como, por exemplo, células gigantes multinucleadas, fibroblastos e fios de sutura foram visualizados. Pôde-se verificar discreto infiltrado inflamatório, constituído por linfócitos e plasmócitos. Aderências (brida) entre o músculo estriado esquelético (de parede abdominal) e a área cicatricial do peritônio visceral também foram encontradas. A mucosa apresentava-se intacta, contudo, com redução na altura e no número de criptas, diminuição da espessura da mucosa, menor celularidade, muscular da mucosa adelgaçada, e até mesmo as camadas musculares apresentavam-se com discreto grau de atrofia. Tais alterações foram visualizadas tanto nos animais do subgrupo A, como também nos ratos do subgrupo $\mathrm{B}$ (Figura $1 \mathrm{~A} / \mathrm{B}$ ).

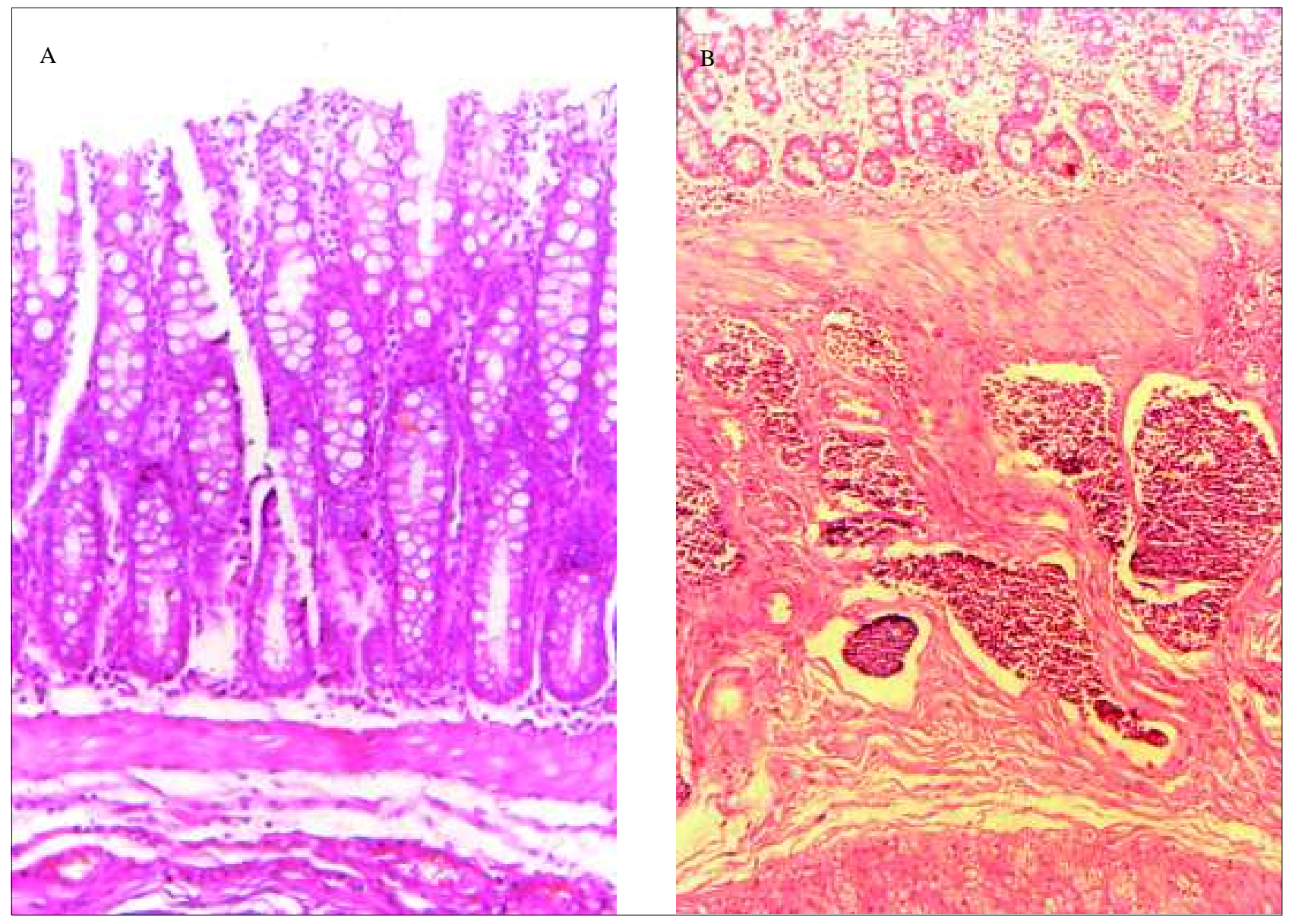

Figura 1 - Fotomicrografia de parede de cólon. À direita (A) histologia de cólon normal aos 60 dias. Em (B) corte histológico de cólon distal de rato aos 60 dias evidenciando diminuição da espessura mucosa, redução na altura e número de criptas, menos celularidade e atrofia das camadas musculares. (He x 40) 


\section{- Coto Distal}

Encontrava-se com marcada hiperplasia linfóide das placas de Peyer. Evidenciaram-se processos inflamatórios agudo e crônico na lâmina própria. Presença de glândulas mucosas ocasionais em submucosa, com áreas de solução de continuidade na muscular da mucosa, foi observada. O reparo cicatricial mural e seroso estava intenso, tendo de permeio agregados linfóides. A mucosa encontrava-se extremamente atrofiada, com diminuição de sua espessura, redução da celularidade e intenso achatamento das criptas. Observou-se, ainda, redução no número de células caliciformes e diminuição da mucossecreção. A muscular da mucosa apresentava-se acentuadamente adelgaçada, com alterações de redução da espessura em todas as camadas da parede colônica. Verificou-se pouca quantidade de tecido de granulação. As células com núcleo fusiforme predominavam no interstício. Observou-se em quatro peças a presença de granulomas com discreta, quase nula, quantidade de tecido necrótico. Tais alterações foram mais intensas nos animais sacrificados no 60 dia de P.O., entretanto, estas não foram estatisticamente significantes.

\section{- Hidroxiprolina}

O peso médio desidratado do segmento de cólon dos animais do grupo controle foi de $0,15 \mathrm{~g}$, sendo $0,16 \mathrm{~g}$ para o subgrupo $\mathrm{C}$ e $0,20 \mathrm{~g}$ para o subgrupo $\mathrm{D}$.

O grupo controle apresentou média de hidroxiprolina de $7,80 \mathrm{mg} / \mathrm{g}$ com desvio padrão de $\pm 0,75 \mathrm{mg} / \mathrm{g}$. A média do conteúdo de hidroxiprolina no subgrupo $\mathrm{C}$ foi de $8,05 \mathrm{mg} / \mathrm{g}$, enquanto que no subgrupo $\mathrm{D}$ foi de $7,21 \mathrm{mg} / \mathrm{g}$.

Os segmentos de coto proximal dos animais do subgrupo A apresentavam peso desidratado médio de $0,38 \mathrm{~g}$. A média do conteúdo de hidroxiprolina no coto proximal, para este subgrupo, foi de $12,68 \mathrm{mg} / \mathrm{g}$ desvio padrão de $\pm 0,97 \mathrm{mg} / \mathrm{g}$.

A média de conteúdo de hidroxiprolina no coto distal dos ratos do subgrupo A encontrava-se em $9,7 \mathrm{mg} / \mathrm{g}$, com desvio-padrão de $\pm 1,36 \mathrm{mg} / \mathrm{g}$. O peso médio desidratado foi de $0,21 \mathrm{~g}$ para os segmentos distais do cólon.

Em relação ao subgrupo B do Grupo I, a média de conteúdo de hidroxiprolina no coto proximal apresentava-se em $7,21 \mathrm{mg} / \mathrm{g}$ e desvio-padrão $\pm 0,06 \mathrm{mg} / \mathrm{g}$. Os valores médios do peso desidratado foi de $0,43 \mathrm{~g}$.

Analisando os segmentos de cólon distais, a média de hidroxiprolina para o subgrupo B foi de $8,45 \mathrm{mg} / \mathrm{g}$, desvio-padrão de $\pm 0,06 \mathrm{mg} / \mathrm{g}$. Peso médio do coto distal dos ratos sacrificados no $60^{\circ}$ dia de P.O. foi de $0,30 \mathrm{~g}$.

Comparando os grupos controle e experimento, não houve diferenças estatisticamente significativas quanto ao conteúdo de hidroxiprolina e peso desidratado (Gráficos 1 e 2).

\section{DISCUSSÃO}

Apesar de, atualmente, a tendência do tratamento cirúrgico após as ressecções colônicas recair sobre a anastomose primária, a colostomia terminal tipo Hartmann, temporária permanece como uma cirurgia bem comum.

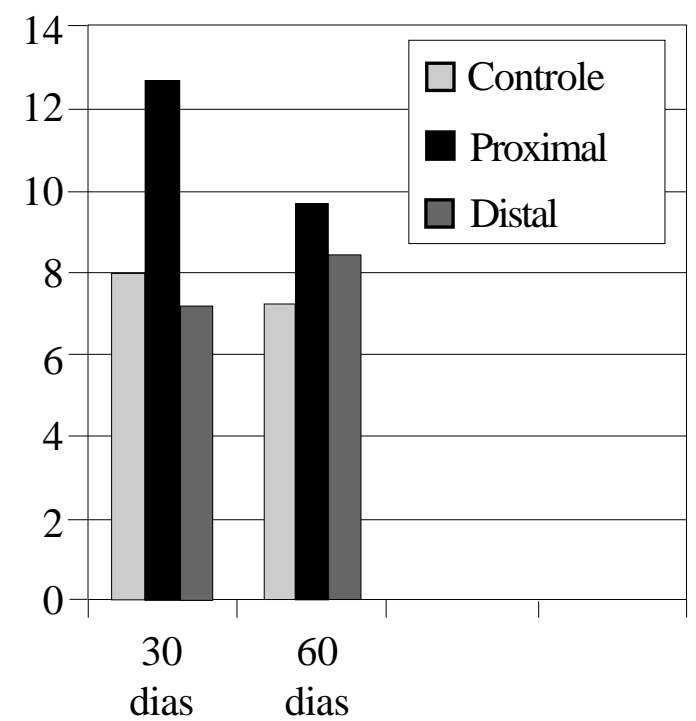

Gráfico 1 - Comparação do conteúdo médio de hidroxiprolina entre os grupos controle e experimento. Subgrupo A (30 dias + proximal e $30+$ distal) Subgrupo B (60 dias + proximal e 60 dias +distal) Subgrupo C (controle +30 dias) Subgrupo D (controle +60 dias).

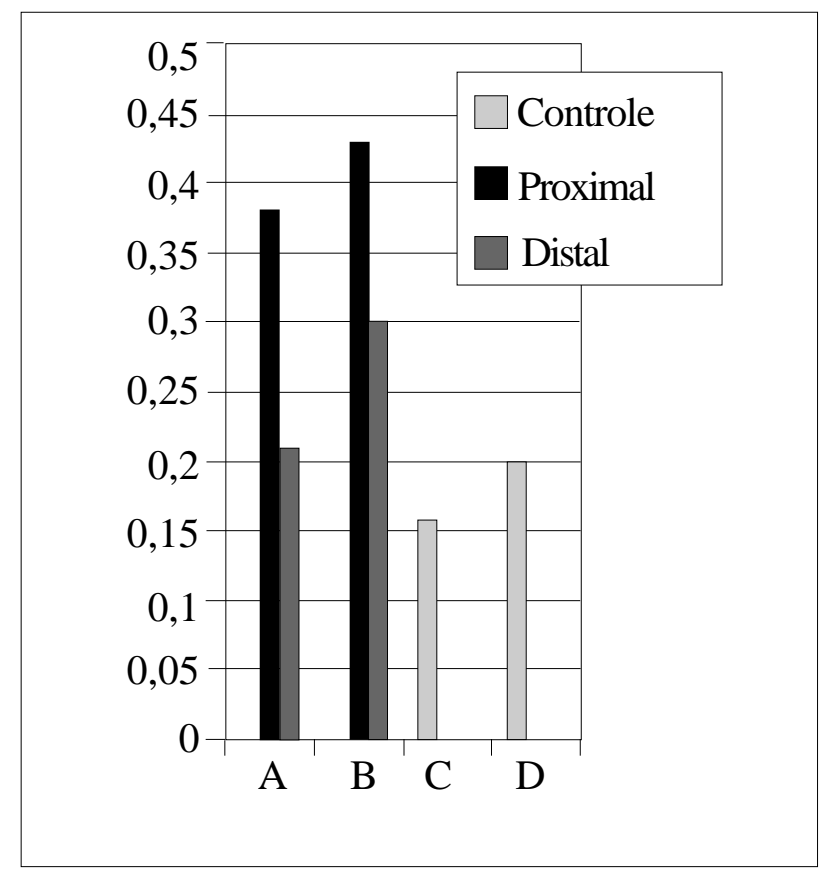

Gráfico 2-Comparação dos pesos médios dos segmentos desidratados entre os subgrupos.

Praticamente, a maioria (2/3) dos pacientes que recebem uma colostomia temporária é candidata à restauração da continuidade do trânsito intestinal após um certo período de pós-operatório ${ }^{3,4,5,6}$. 


\section{Decolostomia}

Apesar da popularidade que a colostomia tipo Hartmann vem alcançando durante os anos, a morbidade e a mortalidade associadas à decolostomia permanecem elevadas $^{4}$. Muitos cirurgiões acreditam que o fechamento da colostomia seja um procedimento de maior morbidade do que a colectomia eletiva ${ }^{6}$.

A morbidade, a mortalidade e o tempo de hospitalização associados ao fechamento da colostomia são, por vezes, maiores do que aqueles dos procedimentos primários. Preferindo-se, atualmente, o fechamento primário das ressecções durante o intra-operatório ${ }^{3}$.

Hartmann não descreveu o procedimento reverso, a decolostomia, mas tal procedimento tornou-se comum quando as circunstâncias o permitem.

$\mathrm{O}$ risco inerente à realização do fechamento da colostomia tem sido bem documentado. Os fatores preditivos para o aumento da morbidade incluem: localização anatômica do estoma, diagnóstico primário que levou à realização da colostomia, anastomose intraperitoneal ou extraperitoneal, anastomose manual ou com o emprego de grampeadores mecânicos, tratamento da ferida operatória e do estoma.

Contudo, a experiência cirúrgica tem demonstrado que a escolha do momento correto do emprego da colostomia e uma técnica cirúrgica meticulosa são as variáveis de maior importância para a morbidade pós-operatória. Deve-se obedecer um tempo mínimo de seis semanas até seis meses entre a criação da colostomia e seu fechamento. Porém, esse intervalo deve ser individualizado para cada paciente. De acordo com Velmahos et al. ${ }^{7}$, o paciente deve permanecer com a colostomia até a total recuperação de suas alterações metabólicas iniciais e de $90 \%$ de seu peso anterior à realização da colostomia.

Alguns autores acreditam que, antes de fazer a indicação cirúrgica da reintegração do trânsito, deve-se realizar radiografia e endoscopia dos segmentos proximal e distal, bem como preparo adequado do cólon, antibioticoterapia profilática adequada, cuidadosa manipulação tecidual e impecável reconstrução anastomótica, promovendo, assim, uma menor taxa de morbi-mortalidade. As técnicas laparoscópicas parecem levar a uma redução na taxa de morbidade dos procedimentos de fechamento das colostomias. ${ }^{8,9}$

A morbidade, segundo Maddern et al. ${ }^{9}$, do fechamento da colostomia é de $35,2 \%$. As complicações e a morbidade, do fechamento da colostomia tipo Hartmann, são $30 \%$ maiores quando comparadas com outras modalidades de ostomias. Contudo, mais recentemente, Wigmore. ${ }^{10}$ referem uma taxa de mortalidade de $0,6 \%$ nas de colostomias tipo Hartmann.

\section{Fechamento Precoce das Colostomias}

O consenso atual é que o fechamento das colostomias temporárias somente se apresenta seguro após três meses da construção inicial.

Complicações com o uso de estomias incluem necrose do estoma, prolapso ou obstrução e a denominada “colite de derivação fecal", descrita por Morson e Dawson, em $1972^{2}$.

Não se encontram bem estabelecidas, as alterações fisiopatológicas relacionadas com a colostomia e o seu fechamento. Contudo, edema periestomal e excessivas quantidades de colágeno são encontrados logo após o procedimento cirúrgico. Parks e Hastings ${ }^{12}$ ressaltam que a presença de edema periestomal ou nos cotos não impede o procedimento cirúrgico, nem sequer eleva os níveis de mortalidade da técnica, devendo a mesma ser realizada, precocemente. Isso permite a utilização da maior síntese de colágeno que ocorre nas primeiras semanas após um procedimento cirúrgico. Dessa forma, tem-se uma cicatrização mais rápida e mais segura.

Roe et al..$^{5}$ relatam que o coto retal após o procedimento Hartmann sofre fenômenos de involução e desfuncionalização, e que no acompanhamento por três meses houve diminuição de $35 \%$ do volume original do coto retal. Estas mudanças estão relacionadas com o fenômeno de colite na mucosa retal e são observadas em praticamente todos os casos num período de três meses de acompanhamento, sendo caracterizado como inflamação crônica com hiperplasia linfóide com ausência de distorções nas criptas ou abscessos. 2,3,4,10,12

Estudos fisiopatológicos têm demonstrado que o volume do coto retal diminui com o tempo após a disfunção. No tempo do procedimento da decolostomia foi clinicamente aparente a diminuição do comprimento do coto distal e o desaparecimento do coto distal no interior da pelve, em muitos pacientes com atraso no fechamento da colostomia, sendo assim indicada a decolostomia, o mais recente possível, antes dos três meses, quando o coto distal retal e colônico é mais acessível. Estas alterações foram econtradas após a eutanásia dos nossos animais submetidos à colostomia tipo Hartmann.

\section{Conteúdo de Hidroxiprolina}

No presente estudo verificamos que o conteúdo de hidroxiprolina dos segmentos proximais e distais encontrava-se em quantidade normal e, até mesmo, elevado, porém não significativo, nas quatro primeiras semanas. Tais achados são compatíveis com a literatura, demonstrando deste modo que, contrariamente ao que se aceitava há alguns anos atrás, existem vantagens marcantes numa reconstituição precoce do trânsito, através da decolostomia. A presença de quantidade normais de hidroxiprolina confere garantia de boa cicatrização, evitando-se, dessa forma, alterações atróficas das camadas colônicas mais acentuadas ou irreversíveis.

Aparentemente, a hipotrofia da mucosa tem lugar, principalmente, nas primeiras quatro semanas após a colostomia, sendo mais acentuada na segunda semana. Estes achados significam que a redução na celularidade epitelial é causada pela diminuição do número total de células decorrente da atividade proliferativa sem mudanças na meia-vida das células epiteliais. Esta diminuição da proliferação celular promove um declínio da área de superfície luminal. 
Blomquist et al. ${ }^{15}$ demonstraram que o desvio do trânsito fecal promove marcada depressão na síntese do colágeno no cólon distal. Isto foi acompanhado por redução do conteúdo do colágeno, juntamente com aumento de sua concentração. Isto é explicado devido à considerável redução das substâncias não colagenosas, as quais constituem a principal parte do tecido de peso desidratado. Assim a concentração do colágeno não representa a real quantidade de colágeno.

Muitos fatores têm sido propostos como sendo influenciadores da hipotrofia do cólon, como, por exemplo: gastrina, alteração da flora bacteriana, estimulação física dos resíduos alimentares na luz intestinal ${ }^{11,15}$. Após todo o intestino ser desviado pela colostomia, o coto distal colônico sofreu progressiva atrofia, com perda de celularidade, principalmente da camada mucosa. Os fatores que regulam o turnover do colágeno na parede intestinal são desconhecidos, mas os achados deste estudo permitem constatar que a presença do conteúdo intestinal estimula as paredes colônicas podendo ser a chave das alterações atróficas encontradas. Essas alterações no conteúdo de colágeno promovem mudanças que afetam o processo de cicatrização e a força mecânica da anastomose das cirurgias colônicas.

A atrofia colônica por desuso após colostomia não se restringe somente à mucosa, atingindo todas as camadas, inclusive a muscular, como foi constatado nos nossos estudos histológicos. A exceção é a camada submucosa que permanece inalterada.

O estudo de Udén et al ${ }^{6}$ revelou que a curto prazo ocorre redução do nível de substâncias não colagenosas (por exemplo, células mucosas e substância intersticial do cólon), enquanto que o conteúdo de colágeno permanece inalterado. Do ponto de vista cirúrgico, isto é de grande interesse, já que o colágeno é a principal fibra protéica da submucosa da parede intestinal responsável pela capacidade da força tênsil das anastomo- ses gastrointestinais. No nosso estudo o colágeno foi determinado indiretamente pelo conteúdo de hidroxiprolina. A hidroxiprolina é um aminoácido encontrado quase que somente no colágeno, onde faz até $14 \%$ do seu peso. A quantidade de colágeno pode ser expressa em termos de concentração deste (que é a quantidade de colágeno em relação ao peso do tecido desidratado) ou conteúdo total de deste.

O prolongado desuso, mesmo que relativo, do intestino reduz as substâncias não colagenosas da parede colônica e causa hipotrofia do tamanho e espessura do cólon.

No presente estudo, também foram verificadas as mais evidentes alterações morfológicas citadas no segmento distal desfuncionalizado. Estas, apresentavamse exuberantes, com hipotrofia de todas as camadas da parede colônica, achatamento das criptas, diminuição da proliferação celular, redução do número de células caliciformes, adelgaçamento da muscular da mucosa, além dos evidentes processos inflamatórios agudo e crônico. Todas estas alterações foram mais evidentemente acentuadas nos animais sacrificados no $60^{\circ}$ de P.O. estando plenamente de acordo com as pesquisas encontradas na literatura. ${ }^{15-18}$

Entretanto, a mensuração dos níveis de hidroxiprolina dos segmentos mostrou-se discordante da maior parte dos estudos da literatura mundial. Estes valores não apresentaram diferenças significantes quando comparadas com o grupo controle e, dessa maneira, não ficou evidenciada a diminuição da hidroxiprolina, e, por conseguinte, a síntese do colágeno. Porém, o presente estudo pode ser enquadrado com a outra linha de pensamento apresentada na literatura. Nestes casos, onde o conteúdo de hidroxiprolina aparece aumentado ou normal pode ser devido à concentração das substâncias colágenas, decorrente da diminuição pronunciada das substâncias não colagenosas.

\begin{abstract}
Colostomy is a commom operative procedure. It is widely used in the treatment of colonic diseases, traumatic injuries and cancer. The main goal of this work was to demonstrate the progressive and adaptive changes in the proximal and distal colon after diverting terminal colostomy (Hartmann's colostomy). These alterations were studied through histologycal examination and the measuring of hydroxyproline content. Forty adult male Wistar rats, weighing $200 \mathrm{~g}$ were divided into two groups of 20 rats each (group I and II ). Each group was divided in another two sub-groups (A,B,C and D) with ten animals each. The rats of $A$ and $B$ sub-groups (group I) were submitted to a median laparotomy to perform Hartmann's colostomy in the distal colon. The animals of the control group were only submitted to a laparotomy. All animals were sacrified on the $30^{\text {th }}$ and $60^{\text {th }}$ postoperative days. Hystological examination demonstrated substantial atrophy of mucosal layer, deteriorations in both crypt size and number, and atrophy of all colonic layers. Other changes included acute and chronic inflammatory infiltrate in the lamina propria.These changes were more intense in distal segments of the animals submitted to Hartmann's colostomy (subgroups A and B). Analysis of the colonic hydroxyproline content were normal in all groups. These findings demonstrated morphologic inflammatory and hypotrophic changes in distal colon after Hartmann's colostomy in rats.
\end{abstract}

Key Words: Hartmann's Colostomy; Hydroxyproline; Rats 


\section{REFERÊNCIAS}

1. Belmante C, Klass JV, Peresz JJ, et al. - The Hartmann's procedure. Arch Surg 1996;131:612-617.

2. Morson BC, Dawson IMP - Gastrointestinal Pathology - $1^{\text {a }}$ edição. Londres: Blackwell Scientific Publications, 1972 ,pp.485.

3. Khoury DA, Beck DE, Opelka FG, et al. - Colostomy Closure. Disease of the Colon e Retun 1996;39:605-609.

4. Mealy K, O’Broin E, Donohue, J, et al. - Revesible colostomy - what is the outcome? Dis Colon Rectun 1996;39:1227-1231.

5. Roe AM, Prabhu S, Ali A, et al. - Reversal of Hartmann's procedure: timing and operative technique. Br J Surg 1991;78:1167-1170.

6. Udén P, Blomsquist P, Jiborn H, et al - Impact of long-term relative bowel rest on conditions for colonic surgery. The American Journal of Surgery 1988;156:381-385.

7. Velmahos GC, Degiannis E, Wells M, et al. - Early closure of colostomies in trauma patients - a prospective randomized trial. Surgery 1995;118:815-820.

8. Kronborg $\mathrm{O}-$ Treatment of perforated sigmoid diverticulitis: a prospective randomized trial. $\mathrm{Br} J$ Surg 1993;80:505-507.

9. Maddern GJ, Nejjari Y, Dennison A, et al - Primary anastomosis with transverse colostomy as an alternative to Hartmann's procedure. Br J Sur 1995;82:170-171.

10. Wigmore SJ, Duthie GS, Young IE, et al - Restoration of intestinal continuity following Hartmann's procedure: the Lothian experience. Br J Surg 1995;82:27-30.

11. Ibbott FA - Aminoacids and related substances. In: HenryRJ;Cannon DC; Winkelman JW - Clinical chemistry principles and technics. $2^{\mathrm{a}}$ edição. New York: Harper \& Row Publishers, 1974, pp.608-614.
12. Clerici C, Gentili G, Boschetti E, et al - Amino acid derivatives of 5-ASA as novel produgs for intestinal drug delivery. Dig Dis Sci 1994; 39:2601-2606.

13. Hollander D - The intestinal permeability barrier. Scand $J$ Gastroenterol 1992;27:721-726.

14. Blomquist $\mathrm{P}$, Jiborn $\mathrm{H}$, Zederfeldt $\mathrm{B}-$ Effect of diverting colostomy on collage metabolism in the colonic wall. Am J Surg 1985;149: 330-333.

15. Parks SE, Hastings PR - Complications of colostomy closure. Am J Surg 1985;149:672-675.

16. Appleton GVN, Williamson RCN - Hypoplasia of defunctioned rectum. Br J Surg 1989;76: 787-789.

17. Wang Q, Pantzar N, Jeppsson B, et al - Increased intestinal marker absorption due to regional permeability changes and decreased intestinal transit during sepsis in the rat. J C C 1995;38:1001-1008.

18. Kissmeyer-Nieslsen P, Christensen H, Lauberg S - Diverting colostomy induces mucosal and muscular atrophy on rat distal colon. GUT 1994;35:1275-1281.

\section{ENDEREÇO PARA CORRESPONDÊNCIA:}

Dr. João Carlos Simões

Rua Nicolau José Gravina, 65

82010-020 - Curitiba-PR

E-mail: drjcs@uol.com.br 